\title{
Notas sobre a recepção e presença do surrealismo no Brasil nos anos 1920-1950 ${ }^{1}$
}

\author{
Robert Ponge
}

O surrealismo começou a vir à luz em 1919, em Paris, com o lançamento da revista Littérature, por André Breton, Philippe Soupault e Louis Aragon, e com a descoberta da escritura "surrealista" (isto é, automática) pelos dois primeiros. Cinco anos depois, em 1924, o surrealismo foi fundado, proclamado movimento explicitamente surrealista, através de várias iniciativas tomadas por um grupo de jovens poetas franceses (o Manifesto de Breton lista 19 nomes) que também reagrupava pintores, fotógrafos e outros artistas e intelectuais, de diversas nacionalidades (Max Ernst era alemão, Man Ray estadunidense, Picasso espanhol etc.).

Pode-se definir brevemente o objetivo do surrealismo como o de lançar e alcançar uma revolução cultural questionadora dos modos vigentes de se expressar, sentir, pensar em primeiro lugar a lógica estreita, fechada, positivista imperante. Cabe assinalar que, desde os primeiros instantes, o surrealismo se destacou como um dos mais vigorosos e instigantes movimentos da modernidade - o que lhe angariou reservas e mesmo reações adversas por parte de diversos setores da intelectualidade francesa (digamos que o leque ia desde alguns colaboradores da modernista Nouvelle Revue française até a monarquista e fascistizante Action française)*. A recepção do surrealismo, portanto, não foi pacífica na própria França, havendo embates a respeito entre, de um lado, partidários da tradição ou de uma modernidade moderada

"(Sobre o assunto, consul. tar, por exemplo: Breton, André. Entretiens (1952). Pa. ris: Gallimard, 1969 - princi. palmente os capítulos ini. ciais -; e Bridel, Yves. Miroirs du suréalisme: Yssair du surréalisme: essai sur la réception du surréalisme en France et en Suisse française (1916-1939). Lausanne: L'Âge d'homme, 1988.) 
"(Sobre o surrealismo na Ar. gentina, devo minhas info mações à tese de doutora. do, bem documentada e pre cisa, do prof. Méndez Cas. tiglioni, bem como à biblio grafia à qual remete. Cf. Méndez Castiglioni, Ruben Da niel. Aldo Pellegrini, surrea lista argentino. Porto Alegre: PUC.RS, 2000.) e, do outro, os surrealistas e seus apoiadores. Vejamos agora quando, e como, o público letrado da América Latina tomou conhecimento desse movimento.

\section{Do Velho Mundo ao Novo}

Por surpreendente que possa parecer, as informações sobre o surrealismo chegaram na América Latina com extrema rapidez; tampouco tardaram os debates. Por exemplo, na Argentina, foi em 1925 (provavelmente no fim do primeiro semestre) que um grupo de estudantes da Universidade de Buenos Aires iniciou uma discussão sobre o novo movimento, a qual desembocou na formação do primeiro grupo surrealista da América Latina e no lançamento da revista Qué (dois números: 1928 e 1930)* No Peru, foi também em 1925 que a imprensa de Lima começou a debater o surrealismo. No Brasil, não foi diferente, como veremos.

Como explicar essa extrema rapidez? Porque já havia bastante tempo que, em conseqüência dos desenvolvimentos da tipografia, dos transportes e das viagens, os debates e a reflexão sobre os rumos da arte vinham se desenvolvendo internacional e, a seguir, intercontinentalmente. E existia um debate internacional porque a arte não possuía mais um caráter local, e sim supranacional. Em outras palavras, o impressionismo, o cubismo, o surrealismo - para citar apenas três exemplos - nasceram em Paris, mas não foram movimentos franceses, foram movimentos internacionais. Nasceram em Paris devido ao lugar especial que, por razões históricas, essa cidade assumiu na vida intelectual e artística da Europa e do planeta a partir do século XVIII, chegando a constituir-se na capital cultural do século XIX e do início do século XX (para parafrasear a conhecida expressão de Walter Benjamin). Outrossim, cabe constatar que, no curso do século XIX e no início do século XX, o fluxo de informações e o ritmo dos contatos internacionais tinham conhecido várias e sucessivas acelerações em decorrência dos imensos progressos dos meios de comunicação (viagens, livros, revistas, imprensa, telegrafia, etc.). O que permite entender como, no bojo do debate internacional sobre a arte moderna e seus rumos, as informações sobre a revista Littérature, André Breton, seus companheiros e seu ideário começaram a chegar à América Latina antes de 1924, no mínimo por volta de 
1922 ou $1923^{2}$. Qual foi a recepção inicial ao surrealismo na América Latina? Diversa e contraditória, como não poderia deixar de ser e como comprovam alguns exemplos. $\mathrm{Na}$ Argentina da segunda metade dos anos 1920 e do início dos anos 1930, poucos repararam a existência do jovem agrupamento surrealista e da revista Qué, pois, conforme o próprio testemunho de seu principal animador, Aldo Pellegrini, o grupo estava "totalmente desvinculado das correntes literárias"* que agitavam o cenário literário argentino, dominado pelo grupo da revista Martín Fierro e pela diferenciação (a seguir, polarização) entre os de Florida e os de Boedo (cujos pólos podem esquematicamente ser definidos como o da literatura dita gratuita ou estetizante e o da literatura dita social). $\mathrm{Pa}-$ rece, portanto, não ter havido embates abertos, explícitos, mas o desprezo; ou, mais simplesmente, a ausência de interesse e a política do silêncio não deixam de ser formas de recepção!

Mas talvez seja o Peru que forneça o melhor exemplo do caráter contraditório da conjuntura intelectual em relação ao surrealismo: em 1925, respectivamente em julho e setembro, nos jornais em que escreviam, José Carlos Mariátegui (intelectual vivo e sensível, marxista aberto às vanguardas) e César Vallejo (poeta, correspondente jornalístico em Paris) deram notícias a respeito da existência do movimento surrealista e das turbulências que, às vezes, provocava em Paris. Ambos voltaram a escrever mais ou menos regularmente sobre o surrealismo entre 1926 e 1930 - a partir de pontos de vistas opostos já que divergiam totalmente na avaliação desse movimento: Mariátegui oferecia um balanço positivo do surrealismo, enquanto Vallejo decretava a morte do mesmo e redigia o laudo de sua autópsia*.

Após esses apontamentos iniciais (que mereceriam ser esmiuçados) sobre as transferências culturais entre a Europa e as Américas e sobre alguns aspectos da recepção do surrealismo na América Latina, podemos nos debruçar sobre a chegada do surrealismo no Brasil.

${ }^{2}$ Neste parágrafo, retomei idéias e formulações apresentadas em "O surrealismo na América Hispânica e no Brasil” (Alea: Estudos Neolatinos, vol. 4, n ${ }^{\circ}$ 1. julho-dezembro 2001. p. 119-132). Para uma análise mais desenvolvida e detalhada dessas questões, ver os itens "Gestação internacional do surrealismo" e "Paris, capital das vanguardas", em: "O surrealismo como via de mão dupla". Em: Bernd, Zilá (org.). Americanidade e transferências culturais. Porto Alegre: Editora Movimento, 2003. p. 90-93 e 96-100.
"(Pellegrini, Aldo. "Carta a Graciela de Sola". Em: Sola, Graciela de. Proyecciones del surrealismo en la literatu. ra argentina. Buenos Aires: Ediciones Culturales Argen. tinas, 1967: 11.)
"(A esse respeito, ver: Lefort, Daniel. "Surrealismo no Peru". Em: Ponge, Robert (org.). Surrealismo e Novo Mundo. Porto Alegre: Edito. ra da UFRGS, 1999: 253, e minha comunicação "O sur. realismo na América Latina: o caso do Peru", nos anais do $2^{\circ}$ Congresso da Associação Brasileira de Hispanistas, Brasileira de Hispanistas, realizado em outubro de
2002, na USP, no prelo.) 
"(Holanda, Sérgio Buarque de. "Entrevista a Maria Célia de Moraes Leonel, em julho de 1975". Em: Leonel, Mari Célia de Moraes. "Estética" e modernismo. São Paulo/ Brasília: Hucitec/INL, Fun dação Nacional Pró-Memó ria, 1984: 178.)
"(Holanda citado por Leonel, Maria Célia de Moraes. "Es. tética" emodernismo. Ob. cit:

tétı.)

\section{Anos 1920, primeiríssimos contatos do Brasil com o surrealismo}

Tudo indica que, no Brasil, no primeiro semestre de 1925 ou, quem sabe, até antes, o surrealismo encontrou ressonância entre a dupla de editores da revista Estética. Liam a Nouvelle Revue française, a revista Commerce (que publicara o ensaio Uma vaga de sonhos, de Aragon) e tudo mais que podiam encontrar. Sérgio Buarque de Holanda e Prudente de Moraes, neto ${ }^{3}$ estavam ansiosos para conhecer, discutir, experimentar novas propostas poéticas e literárias, de onde quer que viessem. De acordo com o testemunho do primeiro, ambos "começa[ram $]$ a escrever cartas surrealistas, conforme a receita de Breton"*.

Quais eram exatamente esses textos automáticos? Não se sabe. Mas não chegaram às páginas da Estética, que, no entanto, publicou, no segundo número (datado de janeiro-março de 1925), um artigo em que Prudente comenta as considerações do crítico francês Benjamin Crémieux sobre o surrealismo, divulgadas pela Nouvelle Revue française, e, no terceiro número (datado de abril-junho de 1925), um ensaio em que Sérgio afirma que "só à noite enxergamos claro", e reivindica "uma declaração dos direitos do sonho"* .

A atitude de Sérgio Buarque de Holanda é curiosa e merece reter nossa atenção: ao falar numa declaração dos direitos do sonho, o autor joga com o prefácio e com o lema da capa do primeiro número de La Révolution Surréaliste, fazendo uma colagem de ambos, mas sem dizê-lo e sem formular uma única vez a palavra surrealista (ou supra-realista, como se usava então). Por que essa postura? Seria cautela? Estariam os dois diretores da revista sondando o terreno dos meios literários brasileiros? Se era essa a sua intenção, ficaram sabendo de várias reações pouco favoráveis, entre as quais as de Mário de Andrade (assaz reticente para com o surrealismo), Graça Aranha, Ronald de Carvalho e Tristão de Athayde (francamente contrários). Apesar disso, Prudente de Moraes, neto não se acanhou e enviou um texto de escritura automática ao jornal $A$ Noite (publicado em 28 de dezembro de 1925) e outro à revista Verde (publicado em novembro de 1927).

${ }^{3}$ É assim mesmo que ele grafava seu nome, com a vírgula e a minúscula. 
Como se percebe, com a dupla Prudente e Sérgio, a árvore modernista brasileira poderia ter produzido um ramo franca e explicitamente surrealista. Mas este não cresceu. Seria interessante pesquisar o porquê. Salvo engano, esse estudo está ainda por ser feito.

Nos anos seguintes, cabe, entre outros dados, assinalar que, em 1927, durante uma viagem à Europa, Ismael Nery entrou em contato (breve?) com Breton e fez amizade com Chagall (que não pertencia ao grupo surrealista e tampouco se considerava surrealista). No Brasil, em 1928, ao fazer a crítica da exposição apresentada por Cícero Dias no salão da Policlínica Geral do Rio de Janeiro, Graça Aranha caracterizou como "pintura surrealista" a obra do artista pernambucano, que, pouco informado sobre esse movimento, estaria, portanto, fazendo - espontânea e ingenuamente - telas surrealistas*. Mas 1928 deve ser relembrado sobretudo como o ano do lançamento da Antropofagia, com revista e manifesto. Neste, Oswald de Andrade não esqueceu de situar - mais ainda, caracterizar - a Antropofagia em relação ao surrealismo ("Já tínhamos o comunismo. Já tínhamos a língua surrealista"*).

Dessa forma, deixava claro que o surrealismo integrava de alguma forma o cabedal antropófago. O que não transformava automaticamente os antropófagos em surrealistas. Por várias razões; entre outras, porque, como veremos, os demais membros do grupo não concordavam necessariamente com Oswald e porque a prática deste não era forçosamente conseqüente com suas palavras.

Independentemente da dose de retórica ou de firme propósito que motivaram esse já tínhamos a língua surrealista, resta que várias telas de Tarsila do Amaral flertaram - namoraram? - então com o surrealismo. E também que, ao chegar ao Brasil, em fevereiro de 1929, com sua esposa brasileira (a cantora lírica Elsie Houston), o poeta surrealista francês Benjamin Péret foi imediatamente saudado pela Revista de Antropofagia com um artigo específico, assinado por Cunhambebinho (ou seja, o próprio Oswald), e aceito como "um antropófago que merece cauins de cacique" e... "precisa ficar entre nós”. Por que precisaria Péret ficar entre os antropófagos? Para que pudesse aprender e crescer com eles? Certamente, mas, sem dúvida, para que os antropófagos pudessem, igual
"(Ver: Aguilar, Nelson. "Cíce. ro Dias e o surrealismo". Em: Ponge Robert (org.). O Brasil e o surrealismo. Porto Ale. gre: Editora da UFRGS, no prelo.)

"(Andrade, Oswald de. "Ma. nifesto antropófago". Revis$1, n^{0}$ 1. São Paulo: maio 1928: 3.) 
"Cunhambebinho. "Péret". dentição, no 1 . Diário de São Paulo, 17 de março de 1929.

"'Cartas na mesa: os Andrades se dividem" (Carta de Carlos Drummond de Andra de a Oswald de Andrade) Revista de Antropofagia. dentição, $n^{\circ} 11$. Diário de São Paulo. 19 de junho de 1929 .) e reciprocamente, conhecer melhor o surrealismo, aprender e crescer com Péret e com esse movimento (elogiado pelo Cunhambebinho porque vinha oferecendo "um dos mais empolgantes espetáculos para qualquer coração de antropófago"). Aliás, a Revista acrescentou taxativamente: "Depois do surrealismo, só a antropofagia"*.

O que afirmava a preeminência do movimento brasileiro por sua capacidade de ingurgitar, mastigar e digerir, assimilando-convertendo-superando as teses e propostas européias. Mas, como o surrealismo era um projeto com um grau de definição muito mais alto e preciso que o movimento brasileiro (o que os antropófagos não ignoravam), essa pequena frase era também um programa e tanto! De fato, tivesse Cunhambebinho-Oswald consciência disso ou não, constituía um verdadeiro desafio, chamando à superação da Antropofagia, para que, em relação ao surrealismo, aquela deixasse de ser uma prima ainda distante ou reservada (porque cultuava uma certa indefinição e heterogeneidade), e se transformasse em uma interlocutora privilegiada, uma amiga do peito, uma autêntica irmã ou, se preferir o leitor, um alter ego. O que, obviamente, só poderia ocorrer por meio de uma complexa alquimia em que a Antropofagia se transformaria, avançaria, mantendo o surrealismo original (Já tínhamos a língua surrealista), preservando o canibalismo impiedoso, integrando as conquistas do surrealismo moderno (1919-1929, e depois) e superando (Aufhebung) todos esses componentes para alcançar uma nova e superior síntese que poderia ou não assumir uma denominação diferente.

Sabe-se que isto não ocorreu. Porque Péret não era bem acolhido por todos os antropófagos (Carlos Drummond de Andrade rompeu com a Revista de Antropofagia pois, entre outros motivos e sem esquecer a possível pitada de provocação, esta “ainda não jant[ara]” Péret, elemento inaceitável no grupo brasileiro "por ser supra-realista e francês”)*. Porque, aos olhos de certos antropófagos, pesavam contra os surrealistas tanto a qualidade de seu engajamento político-revolucionário (declaravam-se marxistas e simpatizantes do comunismo) quanto o fato de sua revolta, sua contestação se estenderem a todos os domínios da vida e do pensamento, incluindo a religião e a própria instituição artístico-literária e seus valores. E, se isso não bastasse, porque a Antropofagia 
se desagregou, explodiu, vítima de sua própria heterogeneidade e da impossibilidade de conciliar suas contradições, sendo o último número da $2^{\mathrm{a}}$ dentição da Revista o $\mathrm{n}^{\circ} 15$, de $1^{\circ}$ de agosto de 1929. Enfim, porque Oswald, em vez de procurar avançar, partindo das conquistas da Antropofagia (seja com uma $3^{\mathrm{a}}$ dentição ou sob nova forma e denominação, na base do menos, mas melhor), resolveu dar as costas a ela, renegá-la e buscar caminho e luz na política cultural da Internacional Comunista, já estalinizada! Ou seja, é como se o desaparecimento da Revista de Antropofagia tivesse tido por conseqüência o esgotamento, por alguns decênios, da possibilidade de efetivo funcionamento de um grupo surrealista antropofagicamente surrealista! - no Brasil.

\section{Anos 1930 e 1940}

Para nos debruçarmos sobre os anos 1930, parece instrutivo iniciar com um paralelo entre Brasil e Argentina no que se refere ao destino do surrealismo em ambos países. Na Argentina, o segundo número da revista Qué saiu datado de dezembro de 1930. Pouco depois, o grupo se dissolveu, segundo Aldo Pellegrini, devido às "intrigas e canalhices de alguns dos componentes"*.

Certamente, mas será preciso esperar o fim dos anos 1940 quase duas décadas - para que torne a surgir um grupo surrealista em Buenos Aires. Será, então, que basta a explicação referente às intrigas e canalhices? No Brasil, a Revista de Antropofagia desapareceu em 1929; será que também por intrigas e canalhices de membros do grupo? Neste caso, sabe-se que havia numerosas divergências, de ordem teórica e sobre os rumos a tomar; novamente, isso basta para explicar?

Parece haver mais que puro acaso nas duas dissoluções quase perfeitamente concomitantes: algo como um sinal dos tempos, sintomático de uma mudança nos ventos pró-vanguardas. Não seria o caso de levar em conta também a conjuntura cultural internacional e a conjuntura política no continente ou, pelo menos, nos dois países aqui citados? No tocante à conjuntura cultural, Pierre Rivas a caracteriza da seguinte forma:

[...] 1930 marca, como é sabido, em toda parte, o tempo do refluxo, o retorno ao tema, ao realismo, a passagem da vanguarda à modernidade. É sobretudo o tempo do confronto entre vanguarda
"(Pellegrini. "Vida, pasión y muerte del surrealismo ar. Bentino". Entrevista a Stefan Surrealismolatinoamericano: preguntasyrespuestas Valpa preguntas y respuestas. Valparaiso (Chile): Ediciones Universitarias de Valparaíso,
1979: 17.) 
e realismo: populismo socialista, neo-realismo, literatura proletária. […]. A especificidade histórico-política dos países periféricos se traduz por uma colocação entre parênteses do avanço surrealista. As ditaduras existentes [...] e as urgências sociais condenam o artista a uma 'má consciência' ou a uma renúncia."

Em apoio à caracterização de Pierre Rivas, cabe lembrar, de passagem, que, nos mais diversos países, a linha cultural dos partidos comunistas começou, no início dos anos 1930, sob a bandeira da literatura proletária, passou para o realismo socialista e desembocou na exaltação do realismo nacional, mas sempre mantendo uma firme oposição à arte moderna e às vanguardas. Quanto aos governos ditos nacionalistas ou populistas (quando não se tratou pura e simplesmente de ditaduras) da América Latina, todos ou quase todos encorajaram uma arte empenhada em caracterizar-se como nacional.

E a conjuntura política? Na Argentina, expressão de uma reação extremamente conservadora, o golpe de Estado liderado pelo general Uriburu abriu as comportas para uma sucessão de governos antidemocráticos, cuja atuação no terreno da cultura não poderia ser ilustrada (Aldo Pellegrini foi preso em 1933, por motivos políticos). No Brasil, a chamada Revolução de 1930 e os sucessivos governos Vargas restringiram cada vez mais as já reduzidas liberdades democráticas (Benjamin Péret foi expulso do Brasil em 1931, acusado de ser um agitador comunista; Flávio de Carvalho sofreu seguidas vezes a repressão etc.), além de convidar os intelectuais a marchar culturalmente sob a bandeira do nacionalismo.

Com efeito, nessa época de franco retorno à ordem política e cultural, o espaço para as vanguardas - e, no caso, para o surrealismo - só podia ser limitado. Vejamos o que isso significou concretamente.

$\mathrm{Na}$ Argentina, as pesquisas desenvolvidas até agora não permitiram encontrar vestígios de vida surrealista coletiva nos anos 1930. Até ignoram-se quais foram as atividades de Pellegrini, além de defender sua tese de doutoramento, fazer a tradução dos Manifestos do surrealismo (para cuja publicação não encontrou editor - pode-se entender por quê) e redigir poemas (que publicou posteriormente, a partir de 1949). Apenas após o fim da Segunda Guerra se registra um reinício das atividades coletivas. 
No Brasil, o surpreendente é que, apesar das condições poucos favoráveis, o mesmo período apresentou vários nomes cuja categorização como surrealista continua diversamente avaliada - reconhecida, discutida, questionada ou negada -, mas cuja obra poética e/ou plástica mantinha relações ou afinidades com as obras dos surrealistas. Assim, quando se fala em surrealismo no Brasil, nos anos 1930, é impossível não fazer, no mínimo, referências a, entre outros, Ismael Nery, Jorge de Lima, Murilo Mendes e Flávio de Carvalho. Também, a partir do início da década de 1940, a Walter Lewy. E, obviamente, à sempre esquecida Maria Martins, cuja obra foi descoberta e reconhecida como surrealista em... Nova Iorque, em 1943, por Breton e seus amigos.

\section{Anos 1950 e 1960}

$\mathrm{O}$ que salientar em termos de surrealismo no Brasil dos anos 1950? Diante da impossibilidade de entrar aqui em questões apontadas anteriormente, limitar-me-ei a destacar três dados. Em primeiro lugar, o retorno de Benjamin Péret ao país, em junho de 1955, com os fins de descansar (estava com sérios problemas de saúde), rever seu filho, reencontrar amigos etc. Durante essa segunda estada brasileira, Péret deu várias entrevistas, redigiu um original e inovador ensaio sobre o quilombo de Palmares*, circulou pelo Norte e o Nordeste, realizou duas viagens para reservas indígenas, adquiriu objetos de arte indígena e popular, bateu muitas fotos e tomou anotações que lhe permitiram escrever vários artigos - assaz informativos, além de poéticos - sobre os índios brasileiros. O que, para os surrealistas, não é secundário, em função de seu apaixonado interesse pelas culturas e artes ditas primitivas.

Em abril de 1956, Péret embarcou de volta para a França. O que, infelizmente, lhe fez perder - por um mês! - algo marcante para o surrealismo: a bela e excepcionalmente ampla (42 esculturas, além de litografias, desenhos, gravuras e alguns objetos de ouro) exposição de Maria Martins apresentada no Museu de Arte Moderna do Rio de Janeiro, cujo catálogo continha três textos: um de Breton, um de Murilo Mendes e um do próprio Péret: " $[\ldots]$ as esculturas de Maria anunciam um mundo que ainda não existe, a menos que ele prolifere alhures, fora da nossa vista; mas debaixo de que céus?”. 
Enfim, deve-se assinalar que, na segunda metade da década, Sergio Lima iniciou sua atividade plástica segundo uma perspectiva surrealista. Viaja à França, encontrando Breton em 1961 e participando das reuniões do grupo parisiense. Após sua volta ao Brasil, impulsionou a formação do grupo surrealista de São Paulo/Rio, o qual, com o apoio do grupo francês, bem como de Maria Martins e de Flávio de Carvalho, organizou a Exposição Internacional do Surrealismo intitulada $A$ mão mágica e o andrógino primordial, realizada em São Paulo, em 1967.

\section{À guisa de conclusão}

Tendo finalizado este breve percurso acerca do surrealismo no Brasil dos anos 1930, 1940 e 1950, o que concluir?

Da mesma forma que na Argentina e no Peru, a recepção ao surrealismo variou bastante. As figuras e correntes mais tradicionais e conservadoras reagiram com antipatia, praticando a política do silêncio e recorrendo vez por outra ao ataque explícito. No campo modernista, registram-se oscilações entre a curiosidade interessada e as reservas (por exemplo, Carlos Drummond e Mário de Andrade), mas também simpatia e mesmo reações entusiásticas, duradouras ou não (Prudente, Sérgio Buarque, Ismael Nery, Oswald, Tarsila, Murilo, Jorge de Lima, Flávio de Carvalho, Lewy, Maria Martins etc.).

O que levanta, no mínimo, duas questões. Uma, que já começou (e apenas começou) a ser discutida e respondida: por que a tese dominante e inconteste, no Brasil, foi durante muito tempo a de que não houve surrealismo no país até os anos 1960, em que bases foi fundamentada tal concepção e em que medida é correta ou não? ${ }^{4} \mathrm{~A}$ outra questão ainda está por

${ }^{4}$ A esse respeito, ver os instigantes ensaios de Flávio Kothe, Sergio Lima e Valentim Facioli na Organon, $\mathrm{n}^{\circ} 22$, intitulada Aspectos do surrealismo, que contém uma seção de cinco artigos dedicados à questão do surrealismo no Brasil (Porto Alegre: Instituto de Letras da UFRGS, 1994, p. 145-206). Como o referido número está esgotado, os três ensaios estão sendo novamente publicados em: Ponge, R. (org.). A recepção das vanguardas literárias e artísticas no Brasil e na América Hispânica. São Paulo: Nankin, no prelo. 
ser investigada: por que, a partir das atividades individuais, contemporâneas entre si, desenvolvidas nos anos 1930 e 1940 - que foram ou são caracterizadas como surrealistas e/ou se autocaracterizaram como tal (mesmo que "à moda brasileira"*) -, não surgiu nenhuma atividade surrealista coletiva?

"(Mendes, Murilo. "André Breton". Em: Poesia completa e prosa. Organização, pre. paração do texto e notas por Luciana Stegagno Picchio. Rio de Janeiro: Nova Aguilar, 1994: 1238.)

Ou terá existido, sem ser até hoje reconhecida? 


\section{Robert Ponge}

Doutor em Letras (USP). Professor titular do Instituto de Letras da Universidade Federal do Rio Grande do Sul (UFRGS). Pesquisador das vanguardas literárias e artísticas, bem como das relações Literatura/História. Organizou o volume Surrealismo e Novo Mundo (Porto Alegre: Editora da UFRGS, 1999), entre outros títulos. Coordena o grupo de pesquisa interinstitucional O surrealismo e seus diálogos com a modernidade: aproximações interdisciplinares (SURRDIAL/CNPq).

Palavras-chave surrealismo recepção diálogos culturais Brasil anos 1920-1950

Key words Surrealism reception cultural dialogues Brazil the 1920-1950s

Mots-clés Surréalisme réception dialogues culturels Brésil

années 1920-1950

Recebido em $15 / 09 / 2003$

O resumo foi traduzido para o inglês por Laura Bocco e para o francês por Vincent Leclercq.

\section{Resumo}

Após brevemente situar o surgimento do surrealismo nos anos 19191924 e apontar alguns elementos dos processos de transferências culturais entre a Europa e as Américas, bem como alguns aspectos da recepção do surrealismo na América Latina, o artigo se debruça sobre a chegada do surrealismo no Brasil, na segunda metade dos anos 1920 e sua expressão na revista Estética e na Antropofagia. A seguir, procura localizar a presença do surrealismo no Brasil dos anos $1930 \mathrm{e}$ 1940, relacionando-a com a conjuntura cultural vigente no período Vargas. Enfim, destaca, nos anos 1950 e 1960, a segunda presença de Benjamin Péret no Brasil, a exposição Maria Martins no MAM-RJ, a atuação de Sérgio Lima e o início do Grupo Surrealista de São PauloRio de Janeiro.

\section{Résumé*}

Après une brève description de l'apparition du surréalisme dans les années 1919-1924, suivie de quelques considérations sur les processus de transferts culturels entre l'Europe et les Amériques, et sur la réception du surréalisme en Amérique latine, l'auteur de cet article se penche sur l'arrivée du surréalisme au Brésil, dans la seconde moitié des années 1920, sur son expression dans la revue Estética, ainsi que dans le mouvement culturel de l'Anthropophagie. Il s'interroge ensuite sur la présence du surréalisme au Brésil dans les années 1930 et 1940, en la situant dans le contexte culturel de la période des gouvernements Var- 
lighting the second stay of Benjamin Péret in Brazil, the Maria Martins exposition at the $\mathrm{Mu}-$ seum of Modern Art of Rio de Janeiro (MAM-RJ), the activities of Sergio Lima and the beginning of the Surrealist Group of São Paulo-Rio de Janeiro. gas. Enfin, l'auteur évoque quelques aspects du surréalisme au Brésil dans les années 1950 et 1960, tels que le deuxième séjour de Benjamin Péret au Brésil, l'exposition Maria Martins au Musée d'Art Moderne de Rio de Janeiro, les activités de Sérgio Lima et les débuts du Groupe surréaliste de São Paulo-Rio de Janeiro. 